\title{
Employee Self-Development or Cyberloafing? The Effects of Occupational Future Time Perspective on Employee's Behaviors
}

\author{
Yaying Li \\ School of Management, Jinan University, Guangzhou, China \\ Email: 599161355@qq.com
}

How to cite this paper: Li, Y. Y. (2021). Employee Self-Development or Cyberloafing? The Effects of Occupational Future Time Perspective on Employee's Behaviors. Journal of Human Resource and Sustainability Studies, 9, 30-42.

https://doi.org/10.4236/jhrss.2021.91003

Received: January 26, 2021

Accepted: March 1, 2021

Published: March 4, 2021

Copyright $\odot 2021$ by author(s) and Scientific Research Publishing Inc. This work is licensed under the Creative Commons Attribution International License (CC BY 4.0).

http://creativecommons.org/licenses/by/4.0/

\begin{abstract}
Based on the socioemotional selectivity theory, this research discusses the relationship between occupational future time perspective and employee selfdevelopment, occupational future time perspective and cyberloafing, and their mechanisms. The results show that there is a dual effect of occupational future time perspective on employee's behaviors. High occupational future time perspective can positively predict employee self-development, which can be partly mediated by the eudaimonic motive. Low OFTP negatively predicted cyberloafing, which can also be partly mediated by the hedonic motive. This study not only enriches the research of OFTP, but also provides some management enlightenments for the organization.
\end{abstract}

\section{Keywords}

Occupational Future Time Perspective, Employee Self-Development, Cyberloafing, Emotional Regulation Motives, Socioemotional Selectivity Theory

\section{Introduction}

Today's society is changing with each passing day. Take the mobile Internet for example, its rapid updating and iteration promotes the rapid integration of various industries and generates the demand for knowledge crossover. Under this background, the continuous learning and development of employees will become the general trend, and many employees adopt employee self-development in order to improve their employability and career adaptability. Employee selfdevelopment (ESD), defined as proactive and self-starting behaviors in compe- 
tency improvement (Ren \& Chadee, 2017). However, in the real work environment, not all employees have the will and action to continue to learn and develop, and the phenomenon of some employees muddling along is also common. Some of them may participate in cyberloafing, the act of employees using their companies' internet access for personal purposes during work hours (Lim \& Teo, 2005). These two very different work behaviors not only affect the personal development of employees, but also have a far-reaching impact on the operation and management of enterprises (Spector et al., 2006; Hameed \& Waheed, 2011). Then, what factors affect different employees' choices of work attitude and behavior? Based on socioemotional selectivity theory (SST), we assumed that employees' perceptions of their future in the employment context, which is called occupational future time perspective (OFTP, Zacher \& Frese, 2009), are an important antecedent of employee's behavior differentiation.

Literature Review found that OFTP is positively related to personal motivation (Kooij \& Van de Voorde, 2011), promotion focus (Baltes, Wynne, Sirabian, Krenn, \& Lange, 2014), and some important work outcomes, including job satisfaction, work engagement, work performance, and organizational citizenship behavior (Schmitt, Zacher, \& De Lange, 2013; Weikamp \& Göritz, 2016). But there is still a research gap above OFTP, motivation and work behavior.

Socioemotional selectivity theory (SST, Lang \& Carstensen, 2002) holds that people differ in their motives depending on their future time perspective. The major goal of the high future time perspective individuals are to gain resources (instrumental), they focus on knowledge acquisition. On the contrary, individuals with low future time perspective pay more attention to obtaining hedonistic rewards, such as emotional satisfaction (Lang \& Carstensen, 2002; Ao, Lv, \& Huang, 2011). OFTP reflects how much remaining time and how many remaining opportunities people perceive themselves as having left in future occupational life (Zacher \& Frese, 2009). This kind of information feedback can stimulate the choice of individual motivation strategy, and then regulate and monitor individual target behavior (Liang, Wu, Lin, Li, \& Zheng, 2017). Socioemotional selectivity theory is an information processing theory of emotion (Bi \& Han, 2014), this research predicts that OFTP will first trigger individual motivation of emotion regulation-eudaimonic motive or hedonic motive, and then affect employee' work behavior. Therefore, emotional regulation motive might be the mediate mechanism of OFTP influencing individual work behaviors. Employees with eudaimonic motive focus on use and develop the best in oneself, in line with one's deeper principles, often associated with self-improvement activities (Huta \& Ryan, 2010), such as employee self-development. Whereas in the hedonic view, well-being is achieved through the pursuit of pleasure, enjoyment, and comfort (Huta \& Ryan, 2010), therefore they are willing to get involved in pleasure-seeking activities, such as cyberloafing.

The purpose of this study is to explore the influence mechanism of employees' OFTP on their goal behaviors, to enrich the application of SST theory. 


\section{Hypotheses}

\subsection{OFTP and Employee Self-Development/Cyberloafing}

Socioemotional selectivity theory (SST, Lang \& Carstensen, 2002) holds that people differ in their motives depending on their future time perspective. Extended to organizational situations, the most direct and important social goal of an individual is his or her work goal, that is, the employee's occupational future time perspective will affect his or her choice of work goals and behaviors (Weikamp \& Göritz, 2016).

Zacher and Fresce (2009) developed the concept of occupational future time perspective (OFTP). The concept of OFTP distinguishes remaining time in occupational future from remaining opportunities in occupational future. Remaining time captures how much time people perceive themselves as having left in future occupational life. Remaining opportunities capture people's beliefs about the number of opportunities for development in their future occupational life.

According to SST, individuals with high FTP perceive their future as open-ended, therefore they focus more on knowledge acquiring and strive hard for the realization of their future. They have knowledge-oriented and future-oriented goals. Employee with high OFTP perceive their future as long and full of opportunities and possibilities, therefore they may imagine and plan their career prospects more clearly, and pay more attention to their own career development. On the one hand, high OFTP employees define their future career selves more clearly, hence they take the initiative to engage in development activities in order to realize their ideal future career selves (Oettingen \& Mayer, 2002). On the other hand, when high OFTP employees face problems, they take the problem-focused and proactive emotion-focused strategy (Ho \& Yeung, 2016). Specifically, high OFTP employees will focus on the distance between the real situation and the future career selves, take the proactive emotion-focused strategy, and take positive actions to gradually shorten the distance.

Employee self-development (ESD) is defined as proactive and self-starting behaviors in competency improvement, which is the corresponding behavior of employees based on their own development needs with the purpose of improving themselves. It can be undertaken through participating in formal training, or through making sense of experiences, or both (Ren \& Chadee, 2017).

To sum up, high OFTP employees have clearer future career vision, they will focus on the distance between their current situation and their future career goals, take positive action, partake in ESD such as spending more time at work seeking the experience of others, or spending money on an MBA program. Thus we have hypothesis 1a:

H1a: There is a positive relationship between OFTP and employee selfdevelopment.

Based on SST, when individuals perceive time as limited and have few remaining opportunities in their occupational future, they will change their moti- 
vational strategies, emotion- and present-oriented goals will be more important. They will focus on short-term, achievable, present gains and adopt a strategy that favors positive emotions and avoids negative ones.

On the one hand, limited OFTP, whether it is the perception of time limited or few remaining opportunities in their occupational future, can lead to negative emotions, such as frustration. Therefore, employees may engage in work withdrawal behavior (Spector et al., 2006). Born in the internet era, cyberloafing means the act of employees using their companies' internet access for personal purposes during work hours ( $\operatorname{Lim} \&$ Teo, 2005). This is the typical way of slacking off during work hours. Some scholars believe that appropriate cyberloafing can be used as a way for employees to cope with tension and stress (Kim, Park, \& Headrick, 2018). Cyberloafing such as online shopping, playing games and chatting with others is a kind of present enjoyment, which can provide employees with immediate leisure comfort experience and bring pleasant mood. Therefore, employees are more willing to engage in activities such as chatting with others for entertainment on the Internet, so as to withdraw work situation to a certain extent and reduce the reception of negative information (Simmers, Anandarajan, \& D'Ovidio, 2008). On the other hand, limited OFTP may make employees feel unfair and dissatisfied, therefore, employees will take self-regulation, and engage in cyberloafing to restore their inner sense of fairness (Ambrose \& Schminke, 2009).

To sum up, the lower the level of employees' OFTP, the more likely they are to engage in cyberloafing.

\section{H1b: There is a negative relationship between OFTP and cyberloafing.}

\subsection{The Mediation Role of Emotional Regulation Motives}

Based on SST, FTP will affect the change of individual motivation, and then influence his choice of social goals (Bi \& Han, 2014). Therefore, we believe that emotional regulation motive might be the key factor affecting the relationship between FTP and social goals.

When faced with emotional event choices, some people want to maximize immediate pleasure. To an extent, they want to feel pleasant emotions and avoid unpleasant ones. Some, otherwise, are willing to sacrifice immediate emotional gratification for useful results, they are "utility-driven". The former is a hedonic motive of emotion regulation, while the latter is an eudaimonic motive of emotion regulation, both of which are motivations of individual activities (Tamir, Chiu, \& Gross, 2007). In the hedonic view, well-being is achieved through the pursuit of pleasure, enjoyment, and comfort, they want to maximize pleasure and avoid negative feelings. However, people with eudaimonic motives, seek to use and develop the best in oneself, in line with one's deeper principles. They are willing to sacrifice the current positive emotional events in order to maximize the beneficial results in the future, in order to exchange for the long-term utilitarian goal reward (Tamir \& Ford, 2012).

OFTP conveys information to employees about opportunities and timing in 
their future careers. Stimulated by this information, employees will form different motivation strategies to achieve self-regulation. Employees with high OFTP not only maintain an optimistic career vision for the future, but also believe that they have a long career future full of possibilities and opportunities, so they are more confident about the realization of future goals, and have a higher expectation of future rewards. This triggers the motivation of utility-driven, and they will be willing to make efforts for better development in their future careers. Based on this, we have hypothesis 2a:

H2a: There is a positive relationship between OFTP and eudaimonic motive.

Mental representations of utility can motivate self-regulation, such that individuals may seek to engage in experiences that they believe are useful (Tamir, Chiu, \& Gross, 2007). Eudaimonic motives are thus focused on aspirations and accomplishments, and scholars conceptualized eudaimonic motives as the perceived importance or preference for job characteristics and work outcomes that relate broadly to achievement and mastery (Kooij \& Van De Voorde, 2011). Thus, when choosing their own target behaviors and activities, eudaimonic employees will pay more attention to the quality of the activity itself, that is, what useful skills can he learn from the activity (Fowers, Mollica, \& Procacci, 2010). Employee self-development (ESD) as proactive and self-starting behaviors in competency improvement, is a typical self-improvement activity undertaken by employees for their future career development.

To sum up, high OFTP employees have optimistic expectations for their career prospects, and have more confidence in achieving their goals. This triggers their eudaimonic motive; Employees with eudaimonic motive desire to developing themselves, therefore, they are more willing to engage in employee self-development.

H3a: Eudaimonic motive mediates the relationship between OFTP and employee self-development, high OFTP may trigger eudaimonic motive, which in turn results in more employee self-development behaviors.

On the contrary, low OFTP employees have limited perception on their career. Based on SST, low OFTP employees shift their motivations from gaining resources (instrumental) to obtaining hedonistic rewards (emotional satisfaction) (Carstensen, 2006). They don't focus on limited negative outcomes in the future and try to avoid work situations that generate negative perceptions. Instead, they focus more on the pleasurable experience of the moment (Bi \& Han, 2014).

Therefore, low OFTP may trigger employees' hedonic motive. We have hypothesis $2 \mathrm{~b}$ :

$\mathrm{H} 2 \mathrm{~b}$ : There is a negative relationship between OFTP and hedonic motive.

Hedonism is the pursuit of feeling good and relaxation. Hedonic motive serves as emotional self-regulation, aimed at restoring one's normal level of mood after it has been disrupted (Vittersø, Søholt, Hetland, Thoresen, \& Roysamb, 2010), or enhancing one's mood, which in turn has a variety of emotional, 
cognitive, and interpersonal benefits (Fredrickson, 2001).

Some scholars believe that cyberloafing is an effective buffer strategy for employees to cope with stressful work situations (Blanchard \& Henle, 2008). Cyberloafing allows employees to temporarily withdraw from the work situation, reducing boredom, exhaustion and stress. This is helpful for the recovery of employees' resources, and increases their positive emotions and subjective vitality (Lim \& Chen, 2012).

In general, low OFTP triggers employees' hedonic motive. Cyberloafing functions as an office toy (Anandarajan \& Simmers, 2005), which can allow employees to obtain pleasant experience and meet their enjoyment needs. Therefore, we have hypothesis $3 \mathrm{~b}$ :

H3b: Hedonic motive mediates the relationship between OFTP and cyberloafing, low OFTP may trigger hedonic motive, which in turn results in more cyberloafing behaviors.

Based on the above hypotheses and inferences, we propose a dual path of OFTP. The overall research framework is shown in Figure 1.

\section{Method}

\subsection{Participants and Procedure}

A sample of 410 Chinese workers participated in the study. After eliminating the questionnaires of respondents with two or more wrong polygraph questions (there were 3 polygraph questions in this questionnaire), 335 valid questionnaires were obtained. Effective recovery is $87 \%$.

There were 163 males and 174 females. In terms of age, workers aged 26 - 35 were the majority (44.5\%), workers under 25 years old accounted for $27.6 \%$, workers aged 36 - 45 years old accounted for 16.3\%, workers aged 46 - 55 years old accounted for 10.1\%, and workers aged over 56 years old accounted for 1.5\%. In terms of working years, the majority (34.7\%) have worked for 1 - 3 years, $22.8 \%$ have worked for less than 1 year, $12.8 \%$ have worked for 3 - 5 years, $15.7 \%$ have worked for 5 - 10 years, and 13.9 have worked for over 10 years. In terms of education, the majority ( $47.5 \%$ ) had a bachelor's degree, $14.5 \%$ had a high school or technical secondary school, $20.8 \%$ had a junior college degree, and $17.2 \%$ had a master's degree or above.

\subsection{Measures}

\section{Occupational Future Time Perspective.}

We used the Occupational Future Time Perspective scale (OFTP) (Zacher and Frese, 2009) to assess how people perceive their occupational future. The scale

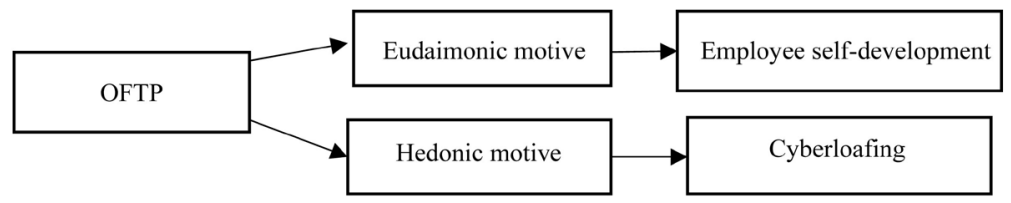

Figure 1. Theoretical model: How OFTP influences employees' behaviors. 
consists of two subscales: remaining time and remaining opportunities. The subscale for remaining time consists of three items and captures how much time people perceive themselves as having left in their occupational future (sample item: "Most of my occupational life lies ahead of me"). Internal consistency, as measured by Cronbach's alpha, was $\alpha=0.75$. The subscale for remaining opportunities consists of three items and captures how many opportunities people perceive themselves as having left in their occupational future (sample item: "Many opportunities await me in my occupational future"). Internal consistency was $\alpha=0.94$. All items were answered on a Likert scale ranging from 1 (does not apply at all) to 7 (applies completely).

\section{Hedonic and Eudaimonic Motives for Activities.}

We used the HEMA scale (Huta and Ryan, 2010) to assess employees' emotional regulation motives. The scale consists of two subscales: eudaimonic motives and hedonic motives. The subscale for eudaimonic motives consists of 4 items (sample item: "Seeking to pursue excellence or a personal ideal?"). Cronbach's alpha was $\alpha=0.87$. The subscale for hedonic motives consists of 5 items (sample item: “Seeking fun?"). Cronbach's alpha was $\alpha=0.89$. The items were rated from 1 (not at all) to 7 (very much).

\section{Employee Self-development.}

We used Ren and Chadee (2017) ESD scale to assess employee self-development. Each item was measured on a 7-point Likert scale, with higher scores indicating higher personal initiatives towards ESD. Sample item as: "evaluate own progress towards learning goals". Cronbach's alpha was $\alpha=0.95$.

\section{Cyberloafing.}

We used a previously validated scale from Jia et al. (2013) to assess cyberloafing. Respondents were asked to indicate on a scale of 1 (Never) to 7 (Constantly), "During office hours, how often do you do the following [non-work-related Internet activities] for personal reasons?". Cronbach's alpha was $\alpha=0.95$ at this research.

\section{Control Variables.}

We controlled for 4 demographics. First, we controlled for age and tenure, because they are negatively associated with OFTP (Zacher \& Frese, 2009). Second, we controlled for gender because women might perceive themselves as having fewer opportunities at work than men do, which may narrow their perception of OFTP. Third, we controlled for education ( 1 = high-school diploma, 2 = junior college, 3 = bachelor's degree, 4 = master's degree and above) because, on average, people with a better education have more occupational possibilities. As a result, they may perceive themselves as having more occupational opportunities (Weikamp \& Göritz, 2016).

\section{Results}

\subsection{Confirmatory Factor Analysis and Common Method Biases Test}

We used confirmatory factor analysis to examine the discriminant validity of 
OFTP, eudaimonic motive, hedonic motive, employee self-development and cyberloafing. Table 1 shows that five-factor model has the best fitting degree $\left(\chi^{2} / \mathrm{df}\right.$ $=3.25$, RMSEA $=0.094, \mathrm{CFI}=0.96, \mathrm{NNFI}=0.96$, SRMR $=0.093)$, which indicates that the above variables have good discriminant validity and represent five different constructs.

The homologous variance was tested by Harman single factor method, the variation explained by the first factor was $37.52 \%$, less than the highest standard $(40 \%)$, so there is no serious problem of common method bias in this study. In addition, considering that the data in this study are all from employees' self-reports, in order to avoid common method deviation, this study made corresponding adjustments in procedures, such as using anonymous answers, reverse statements of some items, etc.

\subsection{Descriptive Statistics and Correlation Analysis}

Table 2 shows means, standard deviations, reliabilities and correlations of study

Table 1. Confirmatory factor analysis results $(N=335)$.

\begin{tabular}{lccccccc}
\hline \multicolumn{1}{c}{ Models } & $\chi^{2}$ & df & $\chi^{2} / \mathrm{df}$ & RMSEA & SRMR & CFI & NNFI \\
\hline 5. factor model (A, B, C, D, E) & 2132.49 & 655 & 3.25 & 0.094 & 0.093 & 0.96 & 0.96 \\
4. factor model (A, B + C, D, E) & 2817.62 & 659 & 4.27 & 0.13 & 0.12 & 0.95 & 0.94 \\
3. factor model (A, B + C, D + E) & 4220.07 & 662 & 6.37 & 0.15 & 0.17 & 0.91 & 0.91 \\
2. factor model (A + B + C, D + E) & 4638.84 & 664 & 6.99 & 0.17 & 0.17 & 0.90 & 0.90 \\
1. factor model (A + B + C + D + E) & 6058.70 & 665 & 9.11 & 0.23 & 0.18 & 0.87 & 0.86 \\
\hline
\end{tabular}

Note: $\mathrm{A}=$ occupational future time perspective, OFTP; $\mathrm{B}=$ eudaimonic motive; $\mathrm{C}=$ hedonic motive; $\mathrm{D}=$ employee self-development, ESD; E = cyberloafing.

Table 2. Variable descriptive statistics and relevant analysis results $(N=335)$.

\begin{tabular}{|c|c|c|c|c|c|c|c|c|c|c|c|}
\hline Variables & $M$ & $S D$ & 1 & 2 & 3 & 4 & 5 & 6 & 7 & 8 & 9 \\
\hline 1. Gender & 1.52 & 0.50 & - & & & & & & & & \\
\hline 2. Age & 2.13 & 0.97 & -0.09 & - & & & & & & & \\
\hline 3. Eudaction & 2.67 & 0.92 & 0.02 & $-0.37^{\star *}$ & - & & & & & & \\
\hline 4. tenure & 2.76 & 1.64 & -0.07 & $0.67^{\star *}$ & $-0.20^{\star \star}$ & - & & & & & \\
\hline 5. OFTPM & 4.41 & 1.46 & -0.07 & -0.08 & 0.08 & $-0.15^{\star *}$ & $(0.86)$ & & & & \\
\hline 6. EM & 5.42 & 1.28 & -0.05 & 0.00 & $0.14^{\star}$ & -0.04 & $0.64^{* *}$ & $(0.87)$ & & & \\
\hline 7. HM & 4.97 & 1.38 & -0.06 & -0.02 & 0.02 & 0.04 & $-0.19^{\star *}$ & $0.24^{\star *}$ & $(0.89)$ & & \\
\hline 8. ESD & 4.65 & 1.32 & $-0.12^{*}$ & 0.08 & $0.14^{* *}$ & -0.05 & $0.64^{* *}$ & $0.72^{\star *}$ & 0.07 & $(0.95)$ & \\
\hline 9. $\mathrm{C}$ & 1.94 & 0.92 & $0.13^{*}$ & $-0.13^{\star}$ & $0.30^{\star *}$ & 0.02 & $-0.47^{\star *}$ & $-0.23^{\star *}$ & $0.26^{* *}$ & $-0.28^{\star *}$ & $(0.97)$ \\
\hline
\end{tabular}

Note: OFTP = occupational future time perspective; EM = eudaimonic motive; $\mathrm{HM}=$ hedonic motive; ESD = employee self-development; $\mathrm{C}=$ cyberloafing. Gender: $1=$ man, 2 = women; Age: 1 = below $25,2=$ 26-35, $3=36-45,4=46-55,5=$ more than 56; Education: $1=$ high-school diploma, $2=$ junior college, $3=$ bachelor's degree, $4=$ master's degree and above; tenure: 1 = below 1 year, $2=1-3$ years, $3=3-5$ years, 4 $=5-10$ years, $5=10-15$ years, $6=15-20$ years, $7=$ more than 20 years, ${ }^{*} p<0.05 ;{ }^{* *} p<0.01$. 
variables. OFTP is significantly positively correlated with eudaimonic motive ( $r$ $=0.64, p<0.01)$, and employee self-development $(r=0.64, p<0.01)$. Also, eudaimonic motive and employee self-development are significantly positively correlated $(r=0.72, p<0.01)$. On the other hand, OFTP is significantly negatively correlated with hedonic motive $(r=-0.19, p<0.01)$, and cyberloafing $(r=$ $-0.47, p<0.01$ ), while hedonic motive and cyberloafing are significantly positively correlated $(r=0.26, p<0.01)$.

\subsection{Hypothesis Test}

Hierarchical regression was used to test the hypothesis in the study. The results are shown in Table 3 . The model 3 shows that OFTP significantly positively predicted employee self-development $(b=0.57, p<0.01)$, hypothesis 1 a was supported. The model 5 shows that OFTP significantly negatively predicted cyberloafing $(b=-0.30, p<0.01)$, hypothesis $1 \mathrm{~b}$ was supported.

Model 1 shows that OFTP significantly positively predicted eudaimonic motive $(b=0.56, p<0.01)$, the results support hypothesis $2 \mathrm{a}$. Model 2 shows that OFTP significantly negatively predicted hedonic motive $(b=-0.18, p<0.01)$, the results support hypothesis $2 \mathrm{~b}$.

Model 4 shows that eudaimonic motive positively predicted employee selfdevelopment $(b=0.51, p<0.01)$, and the positive effect between OFTP and employee self-development is still significant $(b=0.29, p<0.01)$. Thus, eudaimonic motive partially mediates the relationship between OFTP and employee selfdevelopment. According to the method of Hayes (2013), the test results (mediating effect $=0.28$, bias correction CI $95 \%=[0.23,0.37]$ ) support hypothesis 3a.

Table 3. Hierarchical regression results $(N=335)$.

\begin{tabular}{|c|c|c|c|c|c|c|}
\hline \multirow{2}{*}{ Variables } & \multirow{2}{*}{$\begin{array}{c}\begin{array}{c}\text { Eudaimonic } \\
\text { motive }\end{array} \\
\text { M1 }\end{array}$} & \multirow{2}{*}{$\begin{array}{c}\begin{array}{c}\text { Hedonic } \\
\text { motive }\end{array} \\
\text { M2 }\end{array}$} & \multicolumn{2}{|c|}{$\begin{array}{c}\text { Employee } \\
\text { self-development }\end{array}$} & \multicolumn{2}{|c|}{ cyberloafing } \\
\hline & & & M3 & M4 & M5 & M6 \\
\hline Gender & 0.01 & -0.20 & -0.17 & -0.17 & 0.14 & 0.17 \\
\hline Age & 0.10 & -0.11 & $0.32^{\star *}$ & $0.27^{\star *}$ & $-0.13^{*}$ & $-0.12^{*}$ \\
\hline Education & $0.16^{*}$ & 0.04 & $0.22^{\star *}$ & $0.14^{*}$ & $0.27^{\star \star}$ & $0.27^{\star *}$ \\
\hline Tenure & 0.02 & 0.05 & -0.07 & $-0.08^{*}$ & 0.06 & 0.05 \\
\hline OFTP & $0.56^{* *}$ & $-0.18^{\star *}$ & $0.57^{* *}$ & $0.29^{* *}$ & $-0.30^{* *}$ & $-0.28^{* *}$ \\
\hline EM & & & & $0.51^{\star *}$ & & \\
\hline $\mathrm{HM}$ & & & & & & $0.11^{\star *}$ \\
\hline$R^{2}$ & 0.42 & 0.05 & 0.46 & 0.60 & 0.32 & 0.35 \\
\hline$\Delta R^{2}$ & 0.41 & 0.03 & 0.45 & 0.59 & 0.31 & 0.34 \\
\hline$F$ & $47.38^{\star *}$ & $3.12^{* *}$ & $56.02^{* *}$ & $82.52^{* *}$ & $31.51^{\star *}$ & $29.71^{\star *}$ \\
\hline
\end{tabular}

Note: $N=335,{ }^{*} p<0.05 ;{ }^{*} p<0.01$; OFTP $=$ occupational future time perspective; EM = eudaimonic motive; $\mathrm{HM}=$ hedonic motive. 
Similarly, Model 6 shows that hedonic motive positively predicted cyberloafing $(b=0.11, p<0.01)$, and the negative effect between OFTP and cyberloafing is still significant $(b=-0.28, p<0.01)$. Therefore, hedonic motive partially mediates the relationship between OFTP and cyberloafing. According to the method of Hayes (2013), the test results (mediating effect $=-0.02$, bias correction CI $95 \%=[-0.04,-0.01])$ support hypothesis $3 \mathrm{~b}$.

\subsection{Summary}

In conclusion, all research hypotheses were verified.

There is a positive relationship between OFTP and employee self-development, a positive relationship between OFTP and eudaimonic motive. Eudaimonic motive mediates the relationship between OFTP and employee self-development, high OFTP may trigger eudaimonic motive, which in turn results in more employee self-development behaviors.

There is a negative relationship between OFTP and cyberloafing, a negative relationship between OFTP and hedonic motive. Hedonic motive mediates the relationship between OFTP and cuberloafing, high OFTP may trigger hedonic motive, which in turn results in more cyberloafing.

\section{Conclusion}

\subsection{Research Summary}

Based on SST, we explore the influence mechanism of employees' OFTP on their goal behaviors. The results show that after controlling for age, gender, education, and tenure, OFTP can effectively predict employees' disparate goal behavior choices: employees with high OFTP are more inclined to choose self-development behaviors that are conducive to their future career development, while employees with low OFTP are more likely to choose cyberloafing which can provide a pleasurable experience in the present. Among them, eudaimonic motive mediated the relationship between OFTP and employee self-development and the hedonic motive mediated the relationship between OFTP and cyberloafing.

\subsection{Theoretical Significance}

Our study explores the mediating role of emotional regulation motives from the perspective of emotion. Developed from selection optimization and compensation (SOC) theory, SST is a theory of emotional processing (Bi \& Han, 2014). We choose emotional regulation motives as intervening variables, and found that FTP will first trigger the individuals' choice of "useful" or "hedonistic" motivational strategies for emotion regulation, and then affect their target behaviors. The discovery of this mechanism enriches the theory of socioemotional selectivity theory.

\subsection{Practical Significance}

This study focuses on exploring the influence mechanism of OFTP on em- 
ployees' work behaviors differences, which has important reference value for optimizing management practices. After controlling age variables, we found that OFTP could significantly predict employee self-development or cyberloafing. Organizational managers should take actions to improve the employees' OFTP. For example, Zacher and Frese (2009) found that work characteristics (job complexity and control) can alleviate the negative effect of age on the OFTP. The more job complex and controllable workers have on the job, the more optimistically they perceived their future work opportunities, therefore they are more likely to engage in self-development activities and less likely to withdraw from work.

Thus, managers should optimize the work design, enhance employees' OFTP by appropriately increasing the complexity of the work, let employees set their own tasks and let them choose their working methods, etc. Enterprises should further create an atmosphere for development, build a learning organization, and encourage employees to develop themselves. For employees with hedonic motive, some short-term gain incentives should be adopted to reduce cyberloafing.

\subsection{Deficiencies and Prospects}

There are still some limitations and deficiencies in this study. Firstly, the data in this study are based on employee self-statements. Future research can be combined with the implicit method to measure employees' emotional regulation motives, to improve the reliability of the obtained results. Secondly although this study explores the mechanism of OFTP, its boundary role has not been explored. Based on SST, acquisition of knowledge and regulation of emotion are the two main dynamic systems that influence the choice of individual social goal behavior. In specific situations, the two goals will compete with each other (Ao et al., 2011), which means the characteristics of the work situation will affect the employees' motivations and behaviors. Therefore, future research should consider whether the characteristics of work situation can moderate the influence of OFTP on the choice of employees' goal behaviors.

\section{Conflicts of Interest}

The author declares no conflicts of interest regarding the publication of this paper.

\section{References}

Ambrose, M. L., \& Schminke, M. (2009). The Role of Overall Justice Judgments in Organizational Justice Research: A Test of Mediation. Journal of Applied Psychology, 94, 491-503. https://doi.apa.org/doi/10.1037/a0013203

Anandarajan, M., \& Simmers, C. A. (2005). Developing Human Capital through Personal Web Use in the Workplace: Mapping Employee Perceptions. Communications of the Association for Information Systems, 15, 41-48. https://doi.org/10.17705/1CAIS.01541

Ao, L. M., Lv, H. C., \& Huang, X. T. (2011). An Overview of Sioemotional Selectivity 
Theory. Advances in Psychological Science, 19, 217-223.

Baltes, B. B., Wynne, K., Sirabian, M., Krenn, D., \& De Lange, A. (2014). Future Time Perspective, Regulatory Focus, and Selection, Optimization, and Compensation: Testing a Longitudinal Model. Journal of Organizational Behavior, 35, 1120-1133.

https://doi.org/10.1002/job.1970

Bi, D. D., \& Han, B. X. (2014). On the Methodological Issues of Studies on Positivity Effect. Advances in Psychological Science, 22, 1103-1111. https://doi.org/10.3724/SP.J.1042.2014.01103

Blanchard, A. L., \& Henle, C. A. (2008). Correlates of Different Forms of Cyberloafing: The Role of Norms and External Locus of Control. Computers in Human Behavior, 24, 1067-1084. https://doi.org/10.1016/j.chb.2007.03.008

Carstensen, L. L. (2006). The Influence of a Sense of Time on Human Development. Science, 312, 1913-1915. https://doi.org/10.1126/science.1127488

Fowers, B. J., Mollica, C. O., \& Procacci, E. N. (2010). Constitutive and Instrumental Goal Orientations and Their Relations with Eudaimonic and Hedonic Well-Being. The Journal of Positive Psychology, 5, 139-153. https://doi.org/10.1080/17439761003630045

Fredrickson, B. L. (2001). The Role of Positive Emotions in Positive Psychology: The Broaden-and-Build Theory of Positive Emotions. American Psychologist, 56, 218-226. https://doi.apa.org/doi/10.1037/0003-066X.56.3.218

Hameed, A., \& Waheed, A. (2011). Employee Development and Its Affect on Employee Performance a Conceptual Framework. International Journal of Business and Social Science, 2, 224-229.

Hayes, A. F. (2013). Introduction to Mediation, Moderation, and Conditional Process Analysis: A Regression-Based Approach. Journal of Educational Measurement, 51, 335-337. https://doi.org/10.1111/jedm.12050

Ho, H. C., \& Yeung, D. Y. (2016). Effects of Occupational Future Time Perspective on Managing Stressful Work Situations. International Journal of Psychology, 51, 261-268. https://doi.org/10.1002/ijop.12144

Huta, V., \& Ryan, R. M. (2010). Pursuing Pleasure or Virtue: The Differential and Overlapping Well-Being Benefits of Hedonic and Eudaimonic Motives. Journal of Happiness Studies, 11, 735-762. https://doi.org/10.1007/s10902-009-9171-4

Jia, H., Jia, R., \& Karau, S. (2013). Cyberloafing and Personality: The Impact of the Big Five Traits and Workplace Situational Factors. Journal of Leadership \& Organizational Studies, 20, 358-365. https://doi.org/10.1177\%2F1548051813488208

Kim, S., Park, Y., \& Headrick, L. (2018). Daily Micro-Breaks and Job Performance: General Work Engagement as a Cross-Level Moderator. Journal of Applied Psychology, 103, 772-786. https://doi.apa.org/doi/10.1037/apl0000308

Kooij, D. T., \& Van De Voorde, K. (2011). How Changes in Subjective General Health Predict Future Time Perspective, and Development and Generativity Motives over the Lifespan. Journal of Occupational and Organizational Psychology, 84, 228-247. https://doi.org/10.1111/j.2044-8325.2010.02012.x

Lang, F. R., \& Carstensen, L. L. (2002). Time Counts: Future Time Perspective, Goals, and Social Relationships. Psychology and Aging, 17, 125-139. https://doi.apa.org/doi/10.1037/0882-7974.17.1.125

Liang, Q. J., Wu, B. Y., Lin, M. L., Li, F., \& Zheng X. (2017). Relationship between Future Time Perspective and Subjective Well-Being in the College-to-Career Transition: The Multiple Mediation Effects of Social Support and Career Decision-Making Self-Efficacy. Chinese Journal of Clinical Psychology, 25, 1147-1151. 
Lim, V. K. G., \& Chen, D. J. (2012). Cyberloafing at the Workplace: Gain or Drain on Work? Behaviour \& Information Technology, 31, 343-353. https://doi.org/10.1080/01449290903353054

Lim, V. K. G., \& Teo, T. S. H. (2005). Prevalence, Perceived Seriousness, Justification and Regulation of Cyberloafing in Singapore: An Exploratory Study. Information \& Management, 42, 1081-1093. https://doi.org/10.1016/j.im.2004.12.002

Oettingen, G., \& Mayer, D. (2002). The Motivating Function of Thinking about the Future: Expectations versus Fantasies. Journal of Personality and Social Psychology, 83, 1198-1212. https://doi.apa.org/doi/10.1037/0022-3514.83.5.1198

Ren, S., \& Chadee, D. (2017). Is Guanxi Always Good for Employee Self-Development in China? Examining Non-Linear and Moderated Relationships. Journal of Vocational Behavior, 98, 108-117. https://doi.org/10.1016/j.jvb.2016.10.005

Schmitt, A., Zacher, H., \& De Lange, A. H. (2013). Focus on Opportunities as a Boundary Condition of the Relationship between Job Control and Work Engagement: A Multi-Sample, Multi-Method Study. European Journal of Work and Organizational Psychology, 22, 505-519. https://doi.org/10.1080/1359432X.2012.698055

Simmers, C. A., Anandarajan, M., D'Ovidio, R. O. B. (2008). Investigation of the Underlying Structure of Personal Web Usage in the Workplace. Academy of Management Proceedings, 2008, 1-6. https://doi.org/10.5465/ambpp.2008.33649965

Spector, P. E., Fox, S., Penney, L. M., Bruursema, K., Goh, A., \& Kessler, S. (2006). The Dimensionality of Counterproductivity: Are All Counterproductive Behaviors Created Equal? Journal of Vocational Behavior, 68, 446-460. https://doi.org/10.1016/j.jvb.2005.10.005

Tamir, M., \& Ford, B. Q. (2012). Should People Pursue Feelings That Feel Good or Feelings That Do Good? Emotional Preferences and Well-Being. Emotion, 12, 1061-1070. https://doi.apa.org/doi/10.1037/a0027223

Tamir, M., Chiu, C. Y., \& Gross, J. J. (2007). Business or Pleasure? Utilitarian versus Hedonic Considerations in Emotion Regulation. Emotion, 7, 546-554.

https://doi.apa.org/doi/10.1037/1528-3542.7.3.546

Vittersø, J., Søholt, Y., Hetland, A., Thoresen, I. A., \& Roysamb, E. (2010). Was Hercules Happy? Some Answers from a Functional Model of Human Well-Being. Social Indicators Research, 95, Article No. 1. https://doi.org/10.1007/s11205-009-9447-4

Weikamp, J. G., \& Göritz, A. S. (2016). Organizational Citizenship Behaviour and Job Satisfaction: The Impact of Occupational Future Time Perspective. Human Relations, 69, 2091-2115. https://doi.org/10.1177\%2F0018726716633512

Zacher, H., \& Frese, M. (2009). Remaining Time and Opportunities at Work: Relationships between Age, Work Characteristics, and Occupational Future Time Perspective. Psychology and Aging, 24, 487-493. https://doi.apa.org/doi/10.1037/a0015425 